health problems to be employed in increasing awareness and de-stigmatising psychiatric illness. There would have to be high profile approved spokespeople and a public relations unit which courts the media. Television could be used more and the College could instigate documentaries about mental illness. Discussions could be started with television companies so that a mental health night or weekend coincided with the 'relaunch'. An annual National Mental Health Awareness Day could be planned, and combined with bill-posters and even magazine advertisements.

This, however, would be just a start. An experienced public relations team could add to the list of possibilities. But if we did all the above well, we would have taken the first steps to producing a stronger, and better informed, image of who we are and what we are doing.

Kwame McKenzie, Researcher, Institute of Psychiatry, London SE5 8AF

\title{
Training need or travelling roadshow?
}

\section{Michael Shooter and Richard Williams put the spotlight on media workshops for psychiatrists.}

A weasel-faced man in battered trilby and dirty raincoat bludgeons a story from the innocent clinician; the intrepid guardian of the nation's conscience is frustrated by the obscure rantings of a latter-day Frankenstein. These are two easily recognisable stereotypes of media and psychiatry, nurtured through years of mutual mistrust.

There are three possible reactions to our fear of the media - to barricade ourselves against intrusion thus reinforcing the stereotypes; to bury our heads in the sand and hope that the spotlight will move on to another scapegoat; or to join with the media and use them to promote the cause of our clients. Over the last five years, the College has striven hard to develop more constructive relationships with the media through the central activities of the Public Education Department, its Regional and Section Public Education Officers and the bank of experts ready to talk to newspapers, radio or TV on matters of immediate public interest.

All this, of course, demands training. None of us is born a media star. Indeed, many of our quieter, hard-won 'listening' skills make it difficult for us to project ourselves and our subject. The College Officers are now given regular media training by outside professionals, but none of it would be much use without a change of attitude and skills among everyday clinicians. To this end, over the last three years, we have run a whole series of media-training workshops within the programmes of College national, Division and Section meetings throughout the UK - 'bookable' with the right amount of notice!

Requests for our double act come in at least half a dozen times a year. Experience shows that these workshops run best over several hours with a group of participants small enough to remain intimate, large enough to simulate the pressure of an audience. Each opens with a general survey of the College's media aims and activities (the Defeat Depression Campaign, for example, or the series of Help-is-at-Hand leaflets, three million of which have now been distributed). This is followed by a look at the stereotypes we are trying to undermine, during which at least one of the presenters makes a fool of himself - in the interests of a more relaxed atmosphere, of course! And so to the meat of the business. Everyone now has a chance to be interviewed, twice, under the glare of TV arc-lights, in front of their peers, in as near a mock-up of a studio as we can make it, and to be videoed in the process.

On the first time through, the interviewee will have had minimal preparation, the interviewer is surly and interruptive and the whole affair may seem an ordeal. In between times, we have a chance to examine the replayed interviews in every facet of content and process, to offer advice on all stages of presentation from the initial approach to the tape-in-the-can and to practise ways of putting that advice into effect. By the second interview, all participants are guaranteed 
to have improved dramatically as they learn to take control, to everyone's relief - including the interviewer. After all, the media, as well as ourselves, are after good 'copy'; a disaster reflects badly on everyone involved.

These skills are applicable in much wider fields, including our clinical work. All of us face the challenge of influencing the opinions and decisions of others inside and outside our services. Notably, this now includes service purchasers. So the workshops have already spawned court-room skill, job-interview and purchaser-provider offspring.

At the end of the workshop, if the participant goes away determined never to sit down with the media again, so be it. No-one is forced to do so as part of their job. In reality, participants have approached the workshops with the same mixture of excitement and apprehension as they would the media themselves; they have left determined to carry the message out to the community with a new-found confidence. We have nothing to lose but our prejudice!

Michael Shooter, Consultant in Child and Adolescent Psychiatry, Preswylfa Child and Family Centre, Clive Road, Canton, Cardiff CF6 5JL; and Richard Williams, Consultant Child and Adolescent Psychiatrist, Bristol Royal Hospital for Sick Children, St Michael's Hill, Bristol BS2 8BJ

\section{Miscellany}

\section{Honours}

John Gunn, Professor (Forensic Psychiatry), Institute of Psychiatry, was awarded a CBE in the New Year Honours List.

Professor Hugh Freeman has been elected to the Corresponding Membership of the American Psychiatric Association.

\section{Research contacts: European cross-cultural epidemiological study}

In 1994 the Eating Disorders Unit of the University of Innsbruck is planning to start a European multicentre epidemiological study on crosscultural aspects of eating disorders and the impact of the current political, economic, and social changes in the countries of Central and Eastern Europe upon general psychological health, minor psychiatric morbidity and the prevalence of culture-change syndromes. At present, centres from Hungary, the Czech Republic, Poland and Austria are co-operating. Any other participants from Eastern, Central and Western Europe are welcome to join. For further information, please contact the study co-ordinator: Dr Guenther Rathner, Leopold Franzens University of Innsbruck, Department of Pediatrics, Eating Disorders Unit, A-6020 Innsbruck, Austria (fax 435125043444 ).

\section{'Consent to Medical Treatment' poster}

A new poster which summarises patients' rights regarding medical treatment has been published by MIND. It is designed in the style of a flow chart, going through the stages of the decisionmaking process, and the reader is assisted with comments referring to the Mental Health Act 1983 and the Code of Practice, 2nd edition. The poster is available, priced $£ 3.50$ plus $10 \%$ postage and packing, from MIND Publications, 1st Floor, Granta House, 15-19 Broadway, Stratford, London E15 4BQ (telephone 081519 2122).

\section{The Emily Appeal Fund}

The Emily Appeal Fund was launched in 1989 and exists to provide financial support for survivors of child sexual abuse; to collate research data and to publicise the needs of all those who continue to suffer and are unable to get help from the National Health Service and other public services. For further information about the Fund and the regional conferences it will be organising in 1994, please contact: The Emily Appeal Fund. Ashwood, Ashwood Road, Woking, Surrey GU22 7JR (telephone 0483 764666). 